Research Article

\title{
Modification of Lime-Fly Ash-Crushed Stone with Phosphogypsum for Road Base
}

\author{
Hao Zhang $\mathbb{D}^{1}{ }^{1}$ Yuan Cheng $\left(\mathbb{D},{ }^{1}\right.$ Lei Yang, ${ }^{2}$ and Weikang Song ${ }^{1}$ \\ ${ }^{1}$ School of Civil Engineering, Zhengzhou University, Zhengzhou, Henan 450001, China \\ ${ }^{2}$ Henan Information and Statistics Vocational College, Zhengzhou, Henan 450008, China \\ Correspondence should be addressed to Yuan Cheng; chengyuan2008@126.com
}

Received 1 July 2020; Revised 30 October 2020; Accepted 11 November 2020; Published 27 November 2020

Academic Editor: Qiang Tang

Copyright (c) 2020 Hao Zhang et al. This is an open access article distributed under the Creative Commons Attribution License, which permits unrestricted use, distribution, and reproduction in any medium, provided the original work is properly cited.

In order to increase the recycling of phosphogypsum waste, this study explored the feasibility of using phosphogypsum to replace some of the lime and aggregate in the lime-fly ash-crushed stone mixture which is a widely used road base material in China. For this purpose, compaction, compressive strength, composition structures, wetting-drying cycle tests, and shrinkage tests were carried out on the lime-fly ash-phosphogypsum-crushed stone composite to investigate its performance. The results indicate that lime-fly ash-crushed stone modified with phosphogypsum has the required strength of the road base material and favourable performances in environment (wetting-drying cycle) stability. The image processing analysis and shrinkage tests demonstrated that phosphogypsum can significantly improve the compactness and shrinkage performance of lime-fly ash-crushed stone mixture. A suitable content of phosphogypsum and a reasonable content of fine aggregate are conducive to improving the roadway engineering properties (i.e., decreasing shrinkage cracks and increasing compressive strength) of lime-fly ash-phosphogypsum-crushed stone composites.

\section{Introduction}

Phosphogypsum (PG) a by-product from the phosphoric acid industry is a remarkable solid waste, and about $4.5-5.0$ tonnes of dry-based PG is outputted per ton of phosphoric acid (as $\mathrm{P}_{2} \mathrm{O}_{5}$ ) recovered [1]. Approximately 20 million tonnes of $\mathrm{PG}$ is generated in China every year, and its utilization ratio is not more than 10\% [2]. A large amount of it is normally discarded to the environment without any treatment leading to environmental contamination. It has been well documented that PG is an effective modification material for stabilizing special soil and improving the base (or subgrade) behaviors in roadway engineering [2-6]. Studies have been shown that PG alone is not sufficient for road construction. However, it can hasten the pozzuolana reactions between the fly ash (FA) and lime, and the further reaction generates calcium sulfoaluminate hydrate (generally called ettringite) which can bring on a slight expansivity $[2,4,7]$. Therefore, $\mathrm{PG}$ is usually used together with FA and lime to increase strength and reduce shrinkage cracks of road base (or subbase) materials.

For lime-FA-PG binder which is usually applied as subbase material binder, the content of lime is generally $6 \%-$ $12 \%$, and the content of the ratio of PG and FA is usually controlled between $1: 1-1: 4$ [2]. Meanwhile, the content of PG should not be very high because of the expansivity of ettringite [8-10]. However, most of these studies focused on the modification of PG for lime-FA binder or lime-FAstabilized soils. In this paper, the properties of lime-FAcrushed stone (CS) mixture modified with PG are investigated. Lime-FA-CS (or gravel) is a widely used road base material in China [11,12], and it has many advantages such as steady strength development, simple construction, and the utilization of waste FA, but unfortunately the shrinkage cracks often occur, and the early strength of it is very slow. These disadvantages baffle it from being utilized widely $[11,13,14]$. It should be known that the mix ratio of binder and CS (or gravel) is also another factor affecting the 
mixture's strength and anticrack properties. If the content of binder is very low, the strength of mixture will be very low; otherwise, the mixture will easily shrink and crack. The content of aggregate (CS or gravel) is generally $75 \%-80 \%$ for dense skeleton-type mixture, and appropriate amount of fine aggregate $(<2.36 \mathrm{~mm})$ is beneficial to improve the roadway engineering properties (i.e., decreasing shrinkage cracks and increasing compressive strength) of mixture $[13,15,16]$.

In this study, PG was used to replace some amount of the lime and aggregate in the typical lime-FA-CS mixture without changing the dense skeleton structure. The properties and performance of lime-FA-PG-CS composite used as road base material were investigated to prepare it for the wider application.

\section{Materials and Methods}

2.1. Materials. The chemical compositions of lime, FA, and PG are given in Table 1. The lime was supplied from Dasong Lime Ltd. in Nanjing, China, and contains $71.8 \%$ of $\mathrm{CaO}$ and $\mathrm{MgO}$. The FA was obtained from Nanjing Liuhe Thermoelectric Plant, and the amount of $\mathrm{SiO}_{2}, \mathrm{Al}_{2} \mathrm{O}_{3}$, and $\mathrm{Fe}_{2} \mathrm{O}_{3}$ is $72.4 \%$. The PG was obtained from Nanjing Liuhe Chemical Plant, and its major constituent is calcium sulfate, which is $74.0 \%$.

The CS used in this study was collected from a roadway construction site in Nanjing, China. The particle-size distribution of CS is decided by dense skeleton structure and satisfies the demand of Chinese highway road base specifications JTG/T F20-2015 [17] (Figure 1).

2.2. Test Method. The testing mixture of lime-FA-CS and lime-FA-PG-CS were prepared separately, for comparative analysis, and the content of reactive $\mathrm{CaO}(5.4 \%-5.7 \%)$ in these two materials was approximately the same. The mix composition of lime-FA-CS is as follows: lime 8\%, FA $12 \%$, and CS $80 \%$, in which the fine aggregate ranged from $0.06 \mathrm{~mm}$ to $2.36 \mathrm{~mm}$ in size accounting for $8 \%$ of total mass. PG is used to replace part of lime and CS in the lime-FA-CS mixture to prepare the lime-FA-PG-CS mixture containing the following composition: lime 6\%, FA 12\%, PG 6\%, and CS $76 \%$. The effect of fine aggregate was also investigated, and its content was varied from $5 \%, 8 \%$, to $12 \%$.

After storing in a sealed plastic bag for 4 hours, the mixture was compacted into a cylinder mold with the size of $\varnothing 150 \times 150 \mathrm{~mm}^{3}$ to prepare test specimens. The compaction degree of the specimen was $98 \%$. The compaction degree was obtained by dividing the specimen's dry density with the mixture's maximum dry density. The maximum dry density was determined from the modified Proctor compaction test.

The modified Proctor compaction tests of lime-FA-CS and lime-FA-PG-CS were carried out according to the test specification JTG E51-2009 of Chinese Ministry of Transport [18], which is quite similar to AASHTO T180/ASTM D1557 [19, 20].

The unconfined compressive strength tests were also conducted in accordance with the test specification JTG E51$2009[18,21]$. The specimens of unconfined compressive strength test for lime-FA-CS mixture and lime-FA-PG-CS mixture were sealed in a plastic bag and stored in a curing room with a relative humility above $95 \%$ and at a constant ambient temperature of $20 \pm 2^{\circ} \mathrm{C}$. Considering the influence of the curing condition for the specimens, two different curing methods were performed: standard curing and soaking curing. In standard curing, the specimen was cured in the curing room for the designed curing period (e.g., 7 days or 28 days) and was immersed in water for 24 hours before the strength test [9]. In soaking curing, the specimen was cured for 7 days in the curing room and then immersed in water for 21 days. Meanwhile, the stability of the mixtures was also investigated by dry-wet cycle tests. Before the drywet test, the specimens were cured 7 days in the curing room. Then, the specimens were taken and placed in an oven at $60^{\circ} \mathrm{C}$ for 12 hours, followed by immersion in the water for 1 day at an ambient temperature of $25^{\circ} \mathrm{C}$. These two steps were defined as one dry-wet cycle. After 6 successive dry-wet cycles, the strength test was performed. For each data point, six specimens were tested [22].

The composition structures of the mixture samples were studied with computed tomography (CT) and image processing analysis [23-25]. As shown in Figure 2, four sections of the 28-day standard cured strength test specimen were scanned by CT equipment. Then, the CT images were adjusted to grayscale mode and converted to binary segmentation by maximum variance, and then the independent crushed stone image and pore image were obtained by contour tracking programs; finally, the pore area ratio was measured and calculated.

In order to reveal the anticracking property of PGmodified mixture as roadway material, shrinkage tests were also carried out. The shrinkage tests were performed conforming to the procedure of a shrinkage test in JTG E51-2009 [18]. The specimens for shrinkage test were prisms of $100 \mathrm{~mm} \times 100 \mathrm{~mm} \times 400 \mathrm{~mm}$. After the specimens were cured in the curing room for 7 days, comparator probes with dial indicator were set on the specimen end surfaces, and then specimens were placed in a testing room with a relative humility of $60 \pm 5 \%$ and at an ambient temperature of $20 \pm 2^{\circ} \mathrm{C}$ (Figure 3 ). The shrinkage ratio $\left(\varepsilon_{i}\right)$ was measured at each curing age and calculated according to equation (1). Three prism specimens were measured for each data point [26]. After the test, the sample was weighed, and the water loss rate was calculated:

$$
\varepsilon_{i}=\frac{\delta_{i}}{L}
$$

where $\delta_{i}$ is the shrinkage deformation of the specimen at the $i$ th moment and $L$ is the initial length of the specimen.

2.3. Mix Formulas. As shown in Table 2, five mix formulas of typical solidified materials were performed. Compaction characteristics (maximum dry density $\rho_{d \max }$ and optimum moisture content $w_{\text {opt }}$ ) of the mixtures are also summarized in Table 2.

\section{Results and Discussion}

3.1. Compressive Strength. The unconfined compressive strength of different mixtures at 7 days and 28 days of curing 
TABLe 1: Chemical properties of materials used.

\begin{tabular}{lccc}
\hline Constituent (\%) & Lime & FA & PG \\
\hline $\mathrm{SiO}_{2}$ & 1.59 & 44.40 & 7.27 \\
$\mathrm{Al}_{2} \mathrm{O}_{3}$ & 0.79 & 24.90 & 0.56 \\
$\mathrm{CaO}$ & 64.40 & 2.09 & 26.60 \\
$\mathrm{Fe}_{2} \mathrm{O}_{3}$ & 0.49 & 3.10 & 0.28 \\
$\mathrm{MgO}$ & 7.43 & 0.58 & 0.17 \\
$\mathrm{~K}_{2} \mathrm{O}$ & 0.12 & 1.10 & 0.39 \\
$\mathrm{SO}_{3}$ & 0.76 & 0.93 & 36.40 \\
$\mathrm{P}_{2} \mathrm{O}_{5}$ & 0.01 & 0.12 & 1.95 \\
$\mathrm{LOi}$ & 24.30 & 21.49 & 26.00 \\
Loss & 24.27 & 9.80 & 25.95 \\
\hline
\end{tabular}

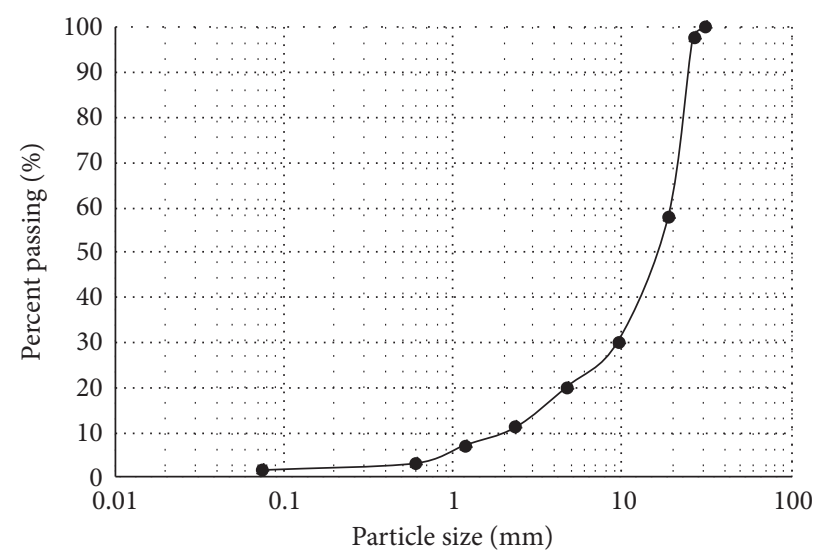

FIGURE 1: The particle-size distribution of CS.
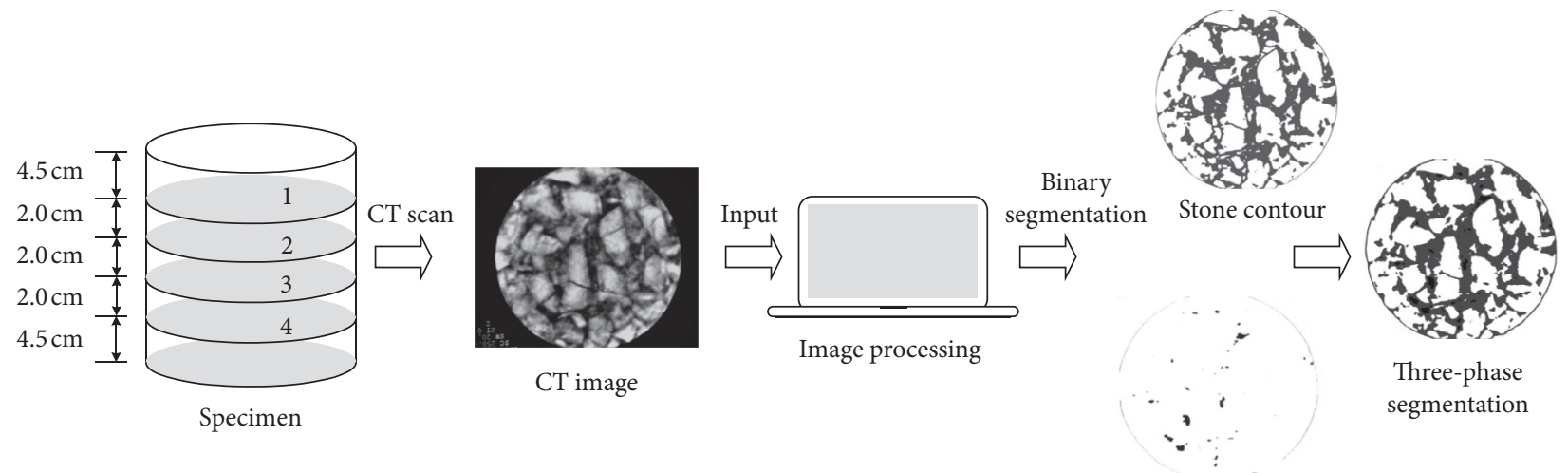

Pore contour

FiguRE 2: Schematic diagram of microstructure analysis.

is shown as Figure 4, in which LFS has higher compressive strength. Although lime-FA-PG-CS mixture has lower compressive strength as it has a lower content of lime and CS, the 7-day unconfined compressive strength of it can reach to $1.1 \mathrm{MPa}-1.4 \mathrm{MPa}$, which meets the requirements of Chinese roadway standard JTG/T F20-2015 [17] for the strength of highway base material. Comparing with PLFS-1, the unconfined compressive strength of PLFS-2 and PLFS-3 with higher content of fine aggregate has an increase of
$11.5 \%$ and $27.6 \%$ at 7 days, respectively. Because of the low content of fine aggregate $(F=5 \%)$, the pores of the coarse aggregate cannot be fulfilled, PLFS-1 has the lowest compressive strength at 28 days. The PLFS- 2 specimens prepared with $8 \%$ fine aggregate have a higher compressive strength at 28 days than the other PG-modified materials (PLFS-1, PLFS-3, and PLFS-4).

The water stability of lime-FA-PG-CS mixtures was studied by comparing with the typical lime-FA-CS road base 


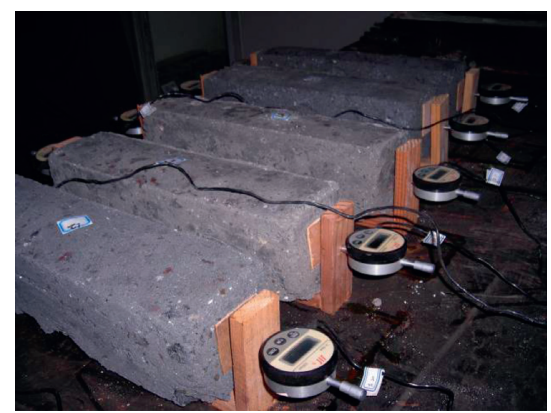

Figure 3: Schematic diagram of the shrinkage test.

TABLE 2: Mix proportions of different materials and the compaction test results.

\begin{tabular}{lccc}
\hline Mix ID & Mix formula & $\rho_{d \max }\left(\mathrm{kg} / \mathrm{m}^{3}\right)$ & $w_{\text {opt }}(\%)$ \\
\hline LFS & $8 \% \mathrm{~L}+12 \% \mathrm{FA}+80 \% \mathrm{CS}(\mathrm{F}=8 \%)$ & 2150 & 8.5 \\
PLFS-1 & $6 \% \mathrm{PG}+6 \% \mathrm{~L}+12 \% \mathrm{FA}+76 \% \mathrm{CS}(\mathrm{F}=5 \%)$ & 2070 & 9.8 \\
PLFS-2 & $6 \% \mathrm{PG}+6 \% \mathrm{~L}+12 \% \mathrm{FA}+76 \% \mathrm{CS}(\mathrm{F}=8 \%)$ & 2095 & 10.0 \\
PLFS-3 & $6 \% \mathrm{PG}+6 \% \mathrm{~L}+12 \% \mathrm{FA}+76 \% \mathrm{CS}(\mathrm{F}=12 \%)$ & 2080 & 10.5 \\
PLFS-4 & $6 \% \mathrm{PG}+8 \% \mathrm{~L}+12 \% \mathrm{FA}+74 \% \mathrm{CS}(\mathrm{F}=8 \%)$ & 2075 & 9.0 \\
\hline
\end{tabular}

L: lime; FA: fly ash; CS: crushed stone; PG: phosphogypsum; F: fine aggregate ranging from $0.06 \mathrm{~mm}$ to $2.36 \mathrm{~mm}$ in size.

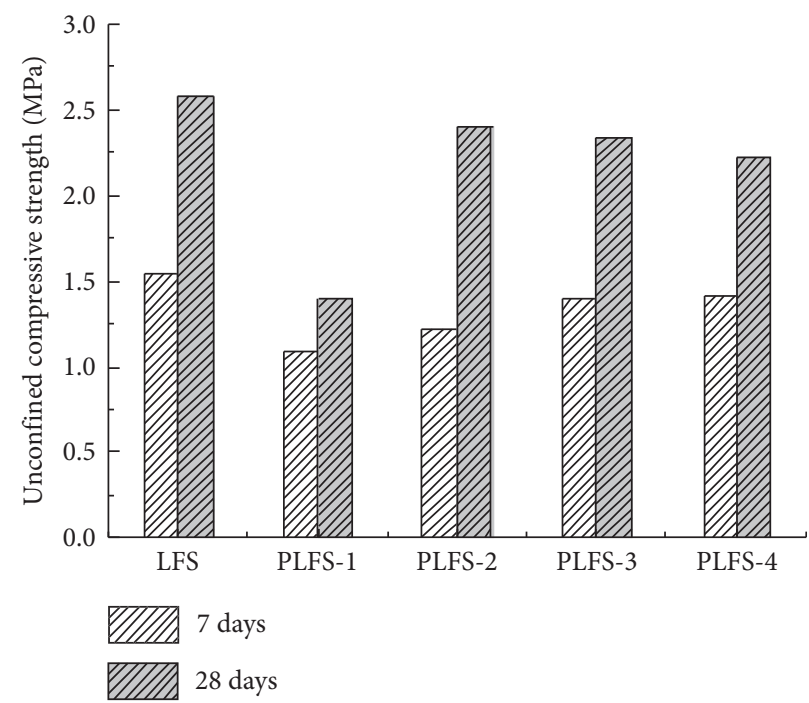

FIGURE 4: Compressive strength of various mixtures.

material. Figure 5 shows the strengths of different mixtures under standard curing condition and soaking curing condition, and it is very clear that all the strengths of the testing specimens under the soaking curing condition at 28 days were lower than those under the standard curing condition. This means that the unconfined compressive strength is weakened by the infiltrating water. Therefore, the PGmodified mixtures used as road base materials in engineering practice cannot be immersed in water at the initial stage of curing, and if it rains during the construction, some covering measures must be taken $[9,10]$. The mass loss of PLFS- 2 and PLFS-3 is $1.8 \%$ and $2.4 \%$, which is as large as LFS $(2.3 \%)$. Compared to them, the mass loss of PLFS- 1 and PLFS-4 almost doubled. This is mainly because the low content of fine aggregate in PLFS-1 prevented the coarse aggregates from being effectively bound together, while the excessive content of blinder in PLFS-4 resulted in the poor integrity.

The dry-wet environment stability of the solidified materials was also studied, and the test results are presented in Figure 6; dry-wet environment stability was assessed with the compressive strength in the specimens after 6 successive dry-wet (DW) cycles. From Figure 6, it can be seen that the strength development of lime-FA-PG-CS mixtures after DW cycles was similar to that of the typical lime-FA-CS road base material, and all the strengths of the specimens increased after 6 cycles of wetting-drying, especially the strength of LFS and PLFS-2 increased by $50.4 \%$ and $57.8 \%$. This is 


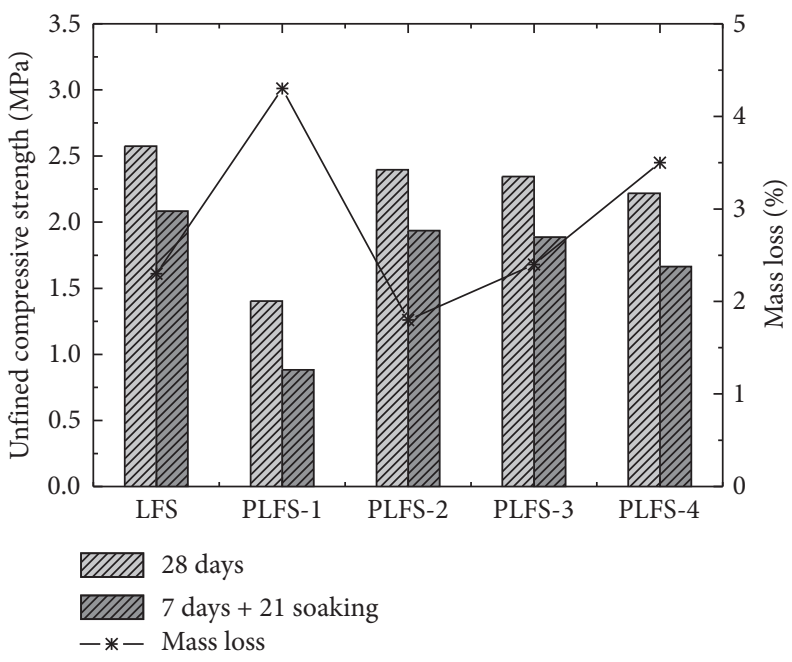

FIGURE 5: The influence of soaking on unconfined compressive strength.

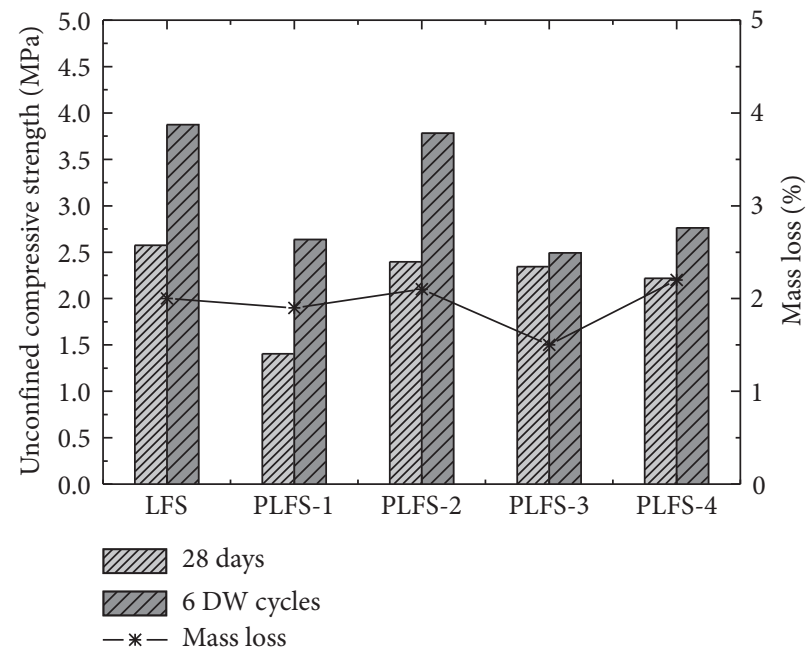

FIGURE 6: The influence of dry-wet cycles on unconfined compressive strength.

mainly because the higher temperature $\left(60^{\circ} \mathrm{C}\right)$ in the drying environment was conducive to the strength development. This behavior indicates that using PG to replace part of lime and CS in typical lime-FA-CS road base material did not reduce the environmental stability.

3.2. Composition Structures of Solidified Material. The composition structures of different solidified materials were analyzed by the image processing method. The second scan section of LFS, PLFS-1, PLFS-2, and PLFS-3 are presented in Figure 7 . In the segmented images, the black color, gray color, and white color represent the air voids, binder which contains the fine aggregate, and coarse aggregates, respectively. The area ratios of coarse aggregate, binder, and voids in the four scan sections are calculated and listed in Table 3. It can be seen that all the solidified materials had good performance, and their void area ratio were no more than $10 \%$; however, the porosity of each section for one specimen is very discrete because of the uneven distribution of coarse aggregate. For PG-modified mixtures, the content of fine aggregate has impact on composition structures. PLFS-2 with $8 \%$ fine aggregate has the smallest void area ratio $(3.8 \%-4.7 \%)$, whereas the void area ratios of PLFS- 1 and PLFS- 3 are higher. The content of fine aggregate of PLFS- 1 is $5 \%$ which may not completely fill the voids between larger particles. On the contrary, the content of fine aggregate of PLFS- 1 is $12 \%$, and more fine aggregate in the binders is prone to dehydration shrinkage cracks. Hence, a reasonable content of fine aggregate can enhance the conjoint points between larger particles and improve the compactness of mixtures.

3.3. Dry Shrinkage. The anticrack ability of different solidified materials can be evaluated by dry shrinkage tests. The test results of four mixtures LFS, PLFS-1, PLFS-2, and PLFS3 are presented in Figure 8. The shrinkage ratio of LFS 


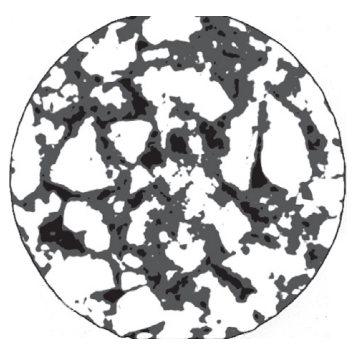

(a)

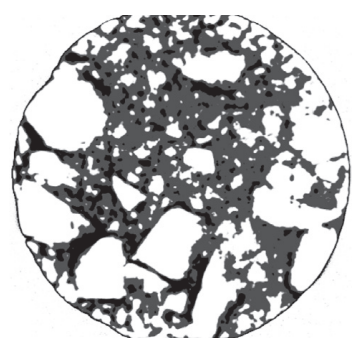

(b)

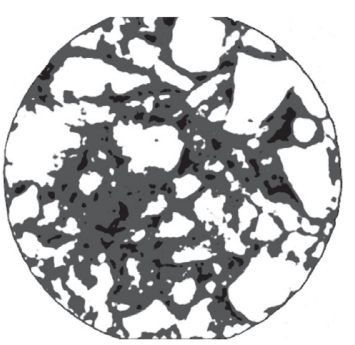

(c)

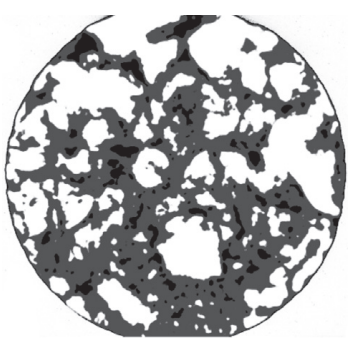

(d)

FIGURE 7: The second section of different solidified materials. (a) LFS. (b) PLFS-1. (c) PLFS-2. (d) PLFS-3.

TABLE 3: Calculation of the composition structures.

\begin{tabular}{|c|c|c|c|c|c|c|c|}
\hline \multirow{2}{*}{\multicolumn{2}{|c|}{ Sections }} & \multirow{2}{*}{$\begin{array}{c}\text { Total } \\
\text { area } \\
\left(\mathrm{cm}^{2}\right)\end{array}$} & \multicolumn{2}{|c|}{ Binder } & \multicolumn{2}{|c|}{$\begin{array}{c}\text { Coarse } \\
\text { aggregate }\end{array}$} & \multirow{2}{*}{$\begin{array}{l}\text { Void area } \\
\text { ratio (\%) }\end{array}$} \\
\hline & & & $\begin{array}{l}\text { Area } \\
\left(\mathrm{cm}^{2}\right)\end{array}$ & $\begin{array}{l}\text { Area } \\
\text { ratio }\end{array}$ & $\begin{array}{l}\text { Area } \\
\left(\mathrm{cm}^{2}\right)\end{array}$ & $\begin{array}{c}\text { Area } \\
\text { ratio } \\
(\%)\end{array}$ & \\
\hline \multirow{4}{*}{ LFS } & 1 & 171.9 & 70.8 & 41.2 & 90.3 & 52.5 & 6.3 \\
\hline & 2 & 168.7 & 50.8 & 30.1 & 101.5 & 60.2 & 9.7 \\
\hline & 3 & 171.2 & 50.9 & 29.7 & 109.9 & 64.2 & 6.1 \\
\hline & 4 & 173.1 & 70.4 & 40.7 & 94.2 & 54.4 & 4.9 \\
\hline \multirow{4}{*}{$\begin{array}{l}\text { PLFS- } \\
1\end{array}$} & 1 & 174.0 & 76.2 & 43.8 & 83.4 & 47.9 & 8.2 \\
\hline & 2 & 174.0 & 64.9 & 37.3 & 95.7 & 55.0 & 7.7 \\
\hline & 3 & 174.0 & 47.0 & 27.0 & 112.8 & 64.8 & 8.2 \\
\hline & 4 & 170.3 & 58.9 & 34.6 & 99.8 & 58.6 & 6.8 \\
\hline \multirow{4}{*}{$\begin{array}{l}\text { PLFS- } \\
2\end{array}$} & 1 & 175.1 & 90.3 & 51.6 & 76.5 & 43.7 & 4.7 \\
\hline & 2 & 174.1 & 82.3 & 47.3 & 85.2 & 48.9 & 3.8 \\
\hline & 3 & 174.6 & 75.3 & 43.1 & 91.1 & 52.2 & 4.7 \\
\hline & 4 & 175.1 & 63.4 & 36.2 & 103.7 & 59.2 & 4.6 \\
\hline \multirow{4}{*}{$\begin{array}{l}\text { PLFS- } \\
3\end{array}$} & 1 & 174.5 & 84.1 & 48.2 & 80.6 & 46.2 & 5.6 \\
\hline & 2 & 174.2 & 81.8 & 47.0 & 83.6 & 48.0 & 5.1 \\
\hline & 3 & 176.0 & 77.3 & 43.9 & 89.1 & 50.6 & 5.5 \\
\hline & 4 & 175.3 & 68.4 & 39.0 & 97.6 & 55.7 & 5.3 \\
\hline
\end{tabular}

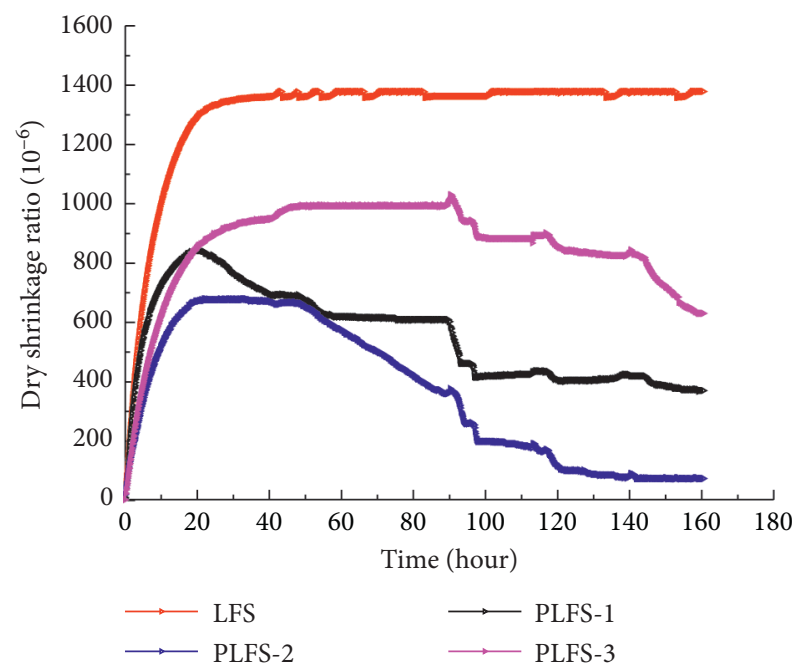

FIGURE 8: Dry shrinkage ratios of various solidified materials. mainly occurred within 0-30 hours, and then the shrinkage ratio tended to be stable, while the dry shrinkage ratios of PG-modified materials (PLFS-1, PLFS-2, and PLFS-3) tended to increase at first and then decrease. The dry shrinkage of the various solidified materials is LFS $>$ PLFS-3 $>$ PLFS$1>$ PLFS-2. PLFS-2 has the lowest shrinkage ratio and has a slight expansivity after curing 160 hours. It is also evident that PG can obviously decrease the dry shrinkage ratio of mixtures due to its enhancement on the pozzuolana reactions and the reaction product AFt's expansivity.

\section{Conclusions}

In this paper, the lime-FA-PG-CS composite is prepared to substitute the typical lime-FA-CS mixture as a road base material. Based on laboratory tests, its mechanical property, composition structures, and volume stability are investigated comparing with the typical lime-FA-CS mixture.

(1) The compressive strength of lime-FA-PG-CS is inferior to that of the typical lime-FA-CS. However, 7day compressive strength of lime-FA-PG-CS reaches 1.1-1.4 MPa with low amount of lime and aggregate, and this strength meets the Chinese standard of road base materials.

(2) Fine aggregate content affects the mechanical properties and composition structures of lime-FAPG-CS. As fine aggregate increases, compressive strength and void area ratio increase first and then decrease. A reasonable content of fine aggregate should be taken into account to improve the strength and composition structure.

(3) In terms of pavement performance of lime-FA-PGCS with good mix formulas (e.g., PLFS-2), the mass loss in immersion is $1.8 \%$ less than the typical limeFA-CS (2.3\%). The compressive strength after drywet cycles increased by $57.8 \%$. And dry shrinkage is significantly less than the typical lime-FA-CS. LimeFA-PG-CS has good performance in volume stability and environment stability.

These results have proved that it is feasible to use PG instead of some lime and aggregate in the typical lime-FACS mixture. The lime-FA-PG-CS composite can be applied as road base material. 


\section{Data Availability}

The data used to support the findings of this study are included within the article.

\section{Conflicts of Interest}

The authors declare that there are no conflicts of interest regarding the publication of this article.

\section{Acknowledgments}

The research presented in this paper was supported by the National Natural Science Foundation of China (Grant no. 42007258), the Key Research and Development Program of Henan Province (Grant no. 202102310302), and the Key Scientific Research Project of Colleges and Universities in Henan Province (Grant no. 18A560024), for which the authors are grateful.

\section{References}

[1] P. Bhawan and E. A. Nagar, "Guidelines for management and handling of phosphogypsum generated from phosphoric acid plants (final draft)," Hazard Waste Manage, 2012.

[2] W. Shen, M. Zhou, and Q. Zhao, "Study on lime-fly ashphosphogypsum binder," Construction and Building Materials, vol. 21, no. 7, pp. 1480-1485, 2007.

[3] N. Degirmenci, A. Okucu, and A. Turabi, "Application of phosphogypsum in soil stabilization," Building and Environment, vol. 42, no. 9, pp. 3393-3398, 2007.

[4] J. James and P. K. Pandian, "Plasticity, swell-shrink, and microstructure of phosphogypsum admixed lime stabilized expansive soil," Advances in Civil Engineering, vol. 2016, pp. 1-10, 2016.

[5] A. Behnood, "Soil and clay stabilization with calcium- and non-calcium-based additives: a state-of-the-art review of challenges, approaches and techniques," Transportation Geotechnics, vol. 17, pp. 14-32, 2018.

[6] T. P. Mashifana, F. N. Okonta, and F. Ntuli, "Geotechnical properties and microstructure of lime-fly ash-phosphogypsum-stabilized soil," Advances in Civil Engineering, vol. 2018, pp. 1-9, 2018.

[7] Z. Si, "Forensic investigation of pavement premature failure due to soil sulfate-induced heave," Journal of Geotechnical and Geoenvironmental Engineering, vol. 134, no. 8, pp. 1201-1204, 2008.

[8] J. Ding, M. Shi, and W. Liu, "Reusing test study and application of phosphogypsum- lime solidified soil in road base course," Journal of Southeast University (Natural Science Edition), vol. 39, no. 1, pp. 121-126, 2009.

[9] J. Ding, M. Shi, W. Liu, and Z. Hong, "In situ stabilization of problematic mixtures in a failed roadway subbase," Journal of Performance of Constructed Facilities, vol. 31, no. 3, Article ID 04017002, 2017.

[10] J. Ding, M. Shi, W. Liu, and X. Wan, "Failure of roadway subbase induced by overuse of phosphogypsum," Journal of Performance of Constructed Facilities, vol. 33, no. 2, Article ID 04019013, 2019.

[11] A. Sha, The Structure and Character of the Semi-rigid Road Base Material, Xi'an Highway University, Beijing, China, 1998.
[12] W. Lu, L. Miao, F. Wang, J. Zhang, Y. Zhang, and H. Wang, "A case study on geogrid-reinforced and pile-supported widened highway embankment," Geosynthetics International, vol. 27, no. 3, pp. 261-274, 2020.

[13] Y. Jiang, Z. Fu, and N. Li, "Design mehtod of LSCR based on mortar theory," Journal of Traffic and Transportation Engineering, vol. 15, no. 5, pp. 8-14, 2015.

[14] W. Lu, Y. Zhang, W. Liu, C. Liu, and H. Wang, "Evaluation of geomembrane effect based on mobilized shear stress due to localized sinking," Advances in Civil Engineering, vol. 2019, Article ID 4942578, 11 pages, 2019.

[15] S. Ma, J. Liu, J. Guo, L. Wang, and X. Chen, "Research on shrinkage performance of dense skeleton based on lime flyash stabilized aggregate," Journal of Chongqing Jiaotong University (Natural Science), vol. 32, no. 2, pp. 215-219, 2013.

[16] W.-h. Lv, T. Wu, F. Gu, and L. Gao, "Evaluation of soil arching effect due to partially mobilized shear stress in piled and geosynthetic-reinforced embankment," Journal of Central South University, vol. 27, no. 7, pp. 2094-2112, 2020.

[17] Ministry of Transport PR China, Technical Guidelines for Construction of Highway Roadbases (JTG/T F20-2015), Ministry of Transport PR China, Beijing, China, 2015.

[18] Ministry of Transport PR China, Test Methods of Materials Stabilized with Inorganic Binders for Highway Engineering (JTG E51-2009), Ministry of Transport PR China, Beijing, China, 2009.

[19] ASTM, Standard Test Methods for Laboratory Compaction Characteristics of Soil Using Modified Effort", ASTM D1557, West Conshohocken, PA, USA, 2000.

[20] AASHTO, Standard Method of Test for Moisture-Density Relations of Soils Using a 4.54-Kg (10-Lb) Rammer and a 457$m m$ (18-in.) Drop"AASHTO T180, Washington, DC, USA, 2015.

[21] W. Lu, J. Wang, and Y. Zhang, "Strength characteristics of cement treated and expanded polystyrene mixed lightweight of waste soil from the construction site of a Yangtze River Bridge in China," Advances in Civil Engineering, vol. 2020, Article ID 3640510, 7 pages, 2020.

[22] W. Shen, M. Zhou, W. Ma, J. Hu, and Z. Cai, "Investigation on the application of steel slag-fly ash-phosphogypsum solidified material as road base material," Journal of Hazardous Materials, vol. 164, no. 1, pp. 99-104, 2009.

[23] N. Otsu, "A threshold selection method from gray-level histograms," Institute of Electrical Electronics Engineers Transactions on Systems, Man, and Cybernetics, vol. 9, no. 1, pp. 62-66, 1979.

[24] F. Altuhafi, C. O'Sullivan, and I. Cavarretta, "Analysis of an image-based method to quantify the size and shape of sand particles," Journal of Geotechnical and Geoenvironmental Engineering, vol. 139, no. 8, pp. 1290-1307, 2013.

[25] Y. Yang, Z. Wei, A. Fourie et al., "Particle shape analysis of tailings using digital image processing," Environmental Science and Pollution Research, vol. 26, no. 25, pp. 26397-26403, 2019.

[26] G. Xu, W. Shen, X. Huo et al., "Investigation on the properties of porous concrete as road base material," Construction and Building Materials, vol. 158, pp. 141-148, 2018. 